\title{
Irrigação de hortaliças por agricultores familiares: uma análise física, química e microbiológica da água
}

A agricultura irrigada proporciona um acréscimo de produtividade nos sistemas agrícolas, no entanto, há necessidade de se observar tanto a quantidade, quanto a qualidade da água disponível, pois a qualidade da água a ser utilizada pode inviabilizar os produtos agrícolas e a segurança alimentar, acarretando contaminações e problemas no sistema de irrigação. Os índices de qualidade da água fornecem uma forma simples de analisar e compreender a real situação, a fim de tomar as medidas necessárias para evitar contaminação e perdas da qualidade da água irrigada na produção. Por tanto, este trabalho teve como objetivo analisar as principais variáveis físico-químicas (turbidez, sólidos totais e pH) e microbiológicas (coliformes termotolerantes) que definem a qualidade da água para irrigação de hortaliças consumidas cruas oriundas de agricultura familiar, as amostras de água foram coletadas em duas réplicas em cada propriedade. Os resultados das análises foram comparadas com a Resolução $n^{\circ}$ 357/05 do CONAMA, para águas de Classe 1 , que são destinadas a irrigação de hortaliças consumidas cruas. Para melhor caracterização da qualidade da água foi feita uma correlação de Pearson ( $r$ ) para analisar a relação entre os parâmetros físicos. Os resultados obtidos mostraram que com exceção do $\mathrm{pH}$, as demais variáveis não apresentaram risco de dano ao sistema de irrigação e a qualidade da água irrigada.

Palavras-chave: Água de irrigação; Qualidade da água; Aspecto físico-químico e microbiológico.

\section{Irrigation of vegetables by family farmers: a physical, chemical and microbiological analysis of water}

Irrigated agriculture provides an increase in productivity in agricultural systems, however, there is a need to observe both the quantity and the quality of the water available, as the quality of the water to be used can make agricultural products and food security unfeasible, leading to contamination and problems in the irrigation system. Water quality indices provide a simple way to analyze and understand the real situation, to take the necessary measures to avoid contamination and losses in the quality of irrigated water in production. Therefore, this work aimed to analyze the main physical-chemical (turbidity, total solids, and $\mathrm{pH}$ ) and microbiological (thermotolerant coliforms) variables that define the water quality for irrigation of vegetables consumed raw from family farming, the water samples were collected in two replicas on each property. The results of the analyzes were compared with CONAMA Resolution No. 357/05, for Class 1 waters, which are intended for irrigation of vegetables consumed raw. To better characterize the water quality, a Pearson ( $r$ ) correlation was made to analyze the relationship between the physical parameters. The results obtained showed that, except for $\mathrm{pH}$, the other variables did not present a risk of damage to the irrigation system and the quality of the irrigated water.

Keywords: Irrigation water; Water quality; Physico-chemical and microbiological aspects.

Topic: Uso de Recursos Naturais

Reviewed anonymously in the process of blind pee
Received: $22 / 04 / 2021$

Approved: 23/05/2021 ítallo Jesus Silva (iD)

Universidade Federal dos Vales do Jequitinhonha e Mucuri, Brasil http://lattes.cnpq.br/3442235540676344 http://orcid.org/0000-0002-4915-6482

talloagro@gmail.com

Graziele Wolff de Almeida Carvalho (iD) Instituto Federal de Minas Gerais, Brasil http://lattes.cnpq.br/31422666547010 http://orcid.org/0000-0001-5299-8878 grazielewolff@yahoo.com.br

Everson Henrique da Silva Vitor

Instituto Federal de Minas Gerais, Brasil

http://lattes.cnpq.br/1272188108704227 everson.vitor.silva@gmail.com

\author{
Deilson de Almeida Alves \\ Universidade Federal dos Vales do Jequitinhonha e Mucuri-Diamantina, Brasil \\ http://lattes.cnpq.br/6962958003151386 \\ http://orcid.org/0000-0002-8524-9010 \\ deilson.almeida.alves@gmail.com \\ Caique Menezes de Abreu (iD \\ Universidade Federal dos Vales do Jequitinhonha e Mucuri-Diamantina, Brasil \\ http://lattes.cnpq.br/3336188708516696 \\ http://orcid.org/0000-0001-8253-4636 \\ abreu.m.caique@gmail.com
}

\section{Referencing this:}

SILVA, I. J.; CARVALHO, G. W. A.; VITOR, E. H. S.; ALVES, D. A.; ABREU, C. M.. Irrigação de hortaliças por agricultores familiares: uma análise física, química e microbiológica da água. Revista lbero Americana de Ciências Ambientais, v.12, n.5, p.587-596, 2021. DOI: http://doi.org/10.6008/CBPC2179-6858.2021.005.0046 


\section{INTRODUÇÃO}

A qualidade da água para a irrigação é de fundamental importância para o uso sustentável na agricultura, no solo, na preservação de equipamentos e na garantir da qualidade da produção que se colhe (MELO et al., 2020). A disponibilidade de água na agricultura depende tanto em termos quantitativos como também qualitativos, cuja quantidade é calculada e a qualidade da água é definida por meio de suas características físicas, químicas e microbiológicas (SOUZA et al., 2020).

Diante da busca pelo desenvolvimento sustentável e do uso racional dos recursos naturais é evidente que a irrigação surge como uma necessidade para obter produtividades satisfatórias, principalmente nas regiões com escassez sazonal de água (REIS et al., 2011). Assim, para que a viabilidade desse processo seja assegurada, é imprescindível dispor de conhecimentos técnicos específicos, que propiciem controle de qualidade eficiente e seguro, o que nem sempre ocorre (ALVES et al., 2021).

Para a qualidade da água, os parâmetros físico-químico e biológico, podem afetar direta ou indiretamente o sistema de irrigação e sua qualidade, de forma que possa está interligada a fonte de captação de água, sendo superficial ou subterrânea (RODRIGUES et al., 2020). A fonte de captação de água usada para irrigação tem consequência na sua qualidade tanto na produção, no tipo de cultura e no solo, de modo apresentar riscos de danos de contaminação a inviabilizar a produção, pois independente de qual for a origem da água, deve ser avaliada e se cumprir os índices de qualidade empíricos necessários para uso de tal fins (ALMEIDA et al., 2008). Existe uma legislação específica no Brasil, que é responsável em estabelecer limites dos fatores físico, químico e biológico para o controle da qualidade da água, que é o Conselho Nacional do Meio Ambiente (CONAMA) com a resolução no 357 de 17 de março de 2005 (BRASIL, 2005). O CONAMA delibera sobre a classificação dos corpos de água e diretrizes ambientais para o seu enquadramento, estabelecendo condições e padrões de lançamento de efluentes (ANA, 2020).

O uso de águas de baixa qualidade em sistemas produtivos irrigados tem sido largamente observado em diversas regiões no Brasil. Este fato demonstra claramente a importância de se realizar o monitoramento dos aspectos qualitativos da água de irrigação e desempenha papel fundamental dentro da pesquisa científica, principalmente quando se utiliza água de baixa qualidade em sistemas produtivos irrigados (ALVES et al., 2021). Tendo em vista que, a água de irrigação é um dos meios de maior fator de influência na quantidade de doenças em hortaliças, faz-se necessário analisar a qualidade das águas utilizadas para irrigação, de maneira mais especial aquelas que irrigam produtos orgânicos tipo hortaliças que são consumidas cruas, que precisam está livre de contaminantes para não causar danos econômicos e sociais (RODRIGUES et al., 2020).

As análises de qualidade de água são instrumento eficiente para a obtenção de informações valiosas quanto à demanda dos recursos hídricos e quanto às restrições ou não ao uso em potencial do manancial (RODRIGUES et al., 2020). Tendo em vista que, a presença de alguns componentes que conferem materiais orgânicos e inorgânicos dissolvidos à água, pode inviabilizar a produção e comercialização de produtos agrícolas (ALMEIDA, 2010). Independente da fonte de recurso da água existe uma necessidade crescente da avaliação do índice de sua qualidade, principalmente de análises microbiológicas e físico- 
químicas (SCHNABEL et al., 2006).

Os índices de qualidade têm como objetivo fornecer ferramentas simples e compreensíveis para identificar a qualidade da água para uso na irrigação (ALMEIDA et al., 2008). O objetivo deste trabalho foi avaliar a qualidade de água para fins de irrigação de hortaliças consumidas cruas oriunda da agricultura familiar, dentre os parâmetros físico-químicas (turbidez, sólidos totais e pH) e biológicos (coliformes termotolerantes).

\section{METODOLOGIA}

O estudo foi realizado no munícipio de São João Evangelista, Estado de Minas Gerais, localizada na região sudeste do Brasil, no vale do Rio Doce, coordenadas geográficas UTM: 736308 m E, 7947136 m S. Zona: 23 K. Datum SIRGAS 2000. Foram avaliadas seis propriedades escolhidas em função da importância da contribuição dos agricultores familiares com alimentação escolar na participação do Programa Nacional de Alimentação Escolar (PNAE). O município exerce importante papel regional com a agricultura como forte atividade econômica, pois se caracteriza por uma agricultura familiar principalmente na produção de hortaliças. Sua vegetação é caracterizada pelo bioma mata atlântica, com clima tropical com estação de seca (IBGE, 2019).
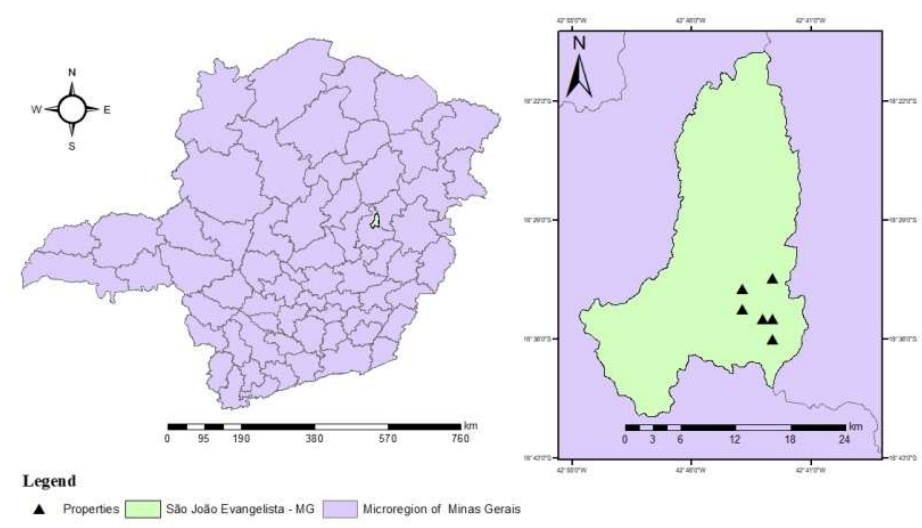

Figura 1: Localização da região de estudo, município de São João Evangelista, microrregião de Minas Gerais, Brasil.

Para a análise da qualidade da água utilizada na irrigação das hortaliças, foram coletadas duas amostras de $500 \mathrm{~mL}$ de água para cada propriedade rural. As amostras foram armazenadas em frascos plásticos, tipo PET, previamente esterilizados. Todas as atividades que envolveram a coleta e a preservação das amostras foram procedidas de acordo com o "Guia de coleta e preservação de amostras de água" (CETESB, 2005). As análises foram realizadas no mesmo dia da coleta seguindo a metodologia proposta pelo Standard Methods for the Examination of Water and Wastewater (APHA, 2005) e foram realizadas no Laboratório de Qualidade de Água do Instituto Federal de Minas Gerais campus São João Evangelista (IFMG-SJE). Foram analisados os parâmetros físico-químicos e biológicos da água como: turbidez, sólidos totais, $\mathrm{pH}$ e coliformes termotolerantes (Escherichia coli).

Para a determinação do $\mathrm{pH}$ utilizou amostra de $100 \mathrm{~mL}$ da água, realizado em medidor de $\mathrm{pH}$ microprocessador, sendo, o medidor de mesa MB10 da fabricante Marte. A análise de turbidez foi determinada pelo turbidímetro Model 2100P ISSO Turbidimeter. Já a analise de sólidos totais foi realizada 
com volume da amostra de água de $100 \mathrm{~mL}$ disposta em capsula de porcelana em estufa a $105^{\circ} \mathrm{C}$ por 24 horas. Logo após esse tempo, colocada em dessecador para esfriar. Realizasse a pesagem das capsulas antes e após realização do procedimento em balança analítica, em seguida com os valores dos pesos, calcula-se os sólidos totais conforme NTS (1999).

Para determinação de coliformes termotolerantes foi utilizado a técnica dos tubos múltiplos, através da qual se obtém o número mais provável (NMP) de microrganismos em $100 \mathrm{~mL}$ de amostra (NMP/100mL) pela observação do números de tubos de cultura positivos (APHA, 2005). Os resultados das análises foram comparados com os valores estabelecidos pela Resolução do CONAMA (Conselho Nacional do Meio Ambiente) $n^{\circ}$ 357, de 17 de março de 2005, para águas de Classe 1, que são destinadas a irrigação de hortaliças consumidas cruas. Os valores dados pela Resolução podem ser observados na Tabela 1.

Tabela 1: Valores para águas de Classe 1 segundo Resolução $n^{\circ} 357 / 05$ do CONAMA

\begin{tabular}{|c|c|}
\hline Parâmetros & Valores \\
\hline $\mathrm{pH}$ & 6,0 a 9,0 \\
\hline Sólidos totais & $500 \mathrm{mg} . \mathrm{L}^{-1}$ \\
\hline Coliformes Termotolerantes & 200 coliformes termotolerantes (NMP) \\
\hline Turbidez & Até 40 unidades nefelométrica (UNT) \\
\hline
\end{tabular}

Os resultados foram comparados quali-quantivamentes quanto os parâmetros físico, químico e biológico perante a resolução $n^{\circ} 357 / 05$. Para melhor caracterização da qualidade da água foi utilizada a correlação de Pearson (r) para analisar a relação entre os parâmetros físicos da qualidade da água.

\section{RESULTADOS E DISCUSSÃO}

Em 50 \% das propriedades rurais do município o parâmetro químico pH estava abaixo do padrão de potabilidade prevista na portaria $n^{\circ} 357 / 05$ do CONAMA classe 1 . A análise física e biológica encontra-se dentro do permitido para irrigação de hortaliças consumidas cruas. Os resultados obtidos em relação as variáveis analisadas permitiu identificar o potencial do uso da água para irrigação de agricultores familiares, além de possibilitar a adequação de práticas de manejo adequado. Os principais resultados das análises das amostras de água perante os parâmetros físico-químicos e microbiológicos avaliados serão representados por gráficos e tabelas. Em relação ao uso da água foi levantado qual tipo de fonte que era usada para utilização na irrigação de hortaliças, sendo água superficial ou subterrânea. 0 resultado é representado na Figura 2.

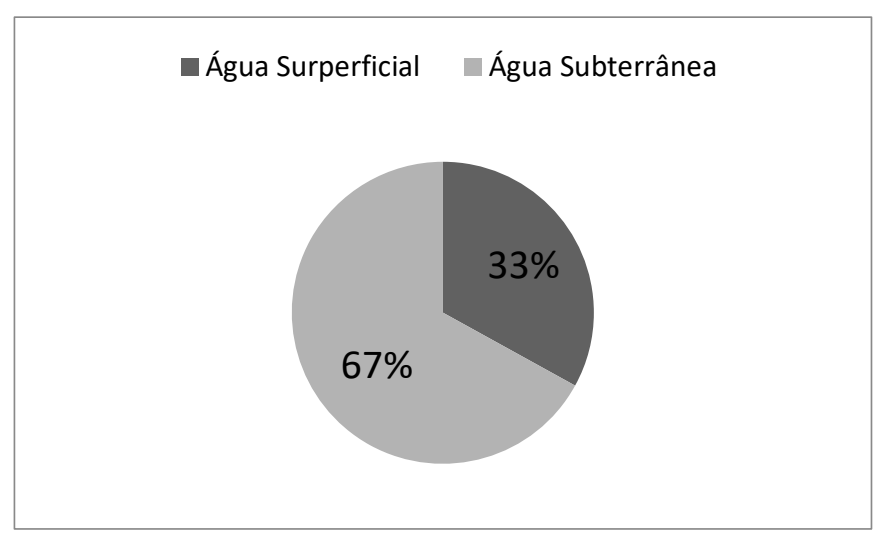

Figura 2: Representação do percentual das fontes de água utilizada na irrigação pelos agricultores rurais do município de São João Evangelista, Estado de Minas Gerais. 
Os resultados obtidos através das análises bacteriológicas das águas utilizadas na irrigação representado pela tabela 2 foram comparados com a resolução do CONAMA 357/2005 para irrigação de hortaliças. A resolução vigente não coloca limites para coliformes totais, sendo permitida a presença dos mesmos. Já para coliformes termotolerantes, estabelece o NMP máximo permitido de 200 coliformes por $100 \mathrm{~mL}$ (BRASIL, 2005).

Tabela 2: Número mais provável (NMP) de coliformes termotolerantes (C.T.) em amostra de água utilizada na irrigação de hortaliças pelos produtores rurais do município de São João Evangelista, Estado de Minas Gerais.

\begin{tabular}{|c|c|c|c|}
\hline Propriedades & Fonte de água utilizada & Amostras & NMP/100 mL C.T. \\
\hline \multirow{2}{*}{ P1 } & \multirow{2}{*}{ Superficial } & $1 \underline{a}$ & 11 \\
\hline & & $2 \underline{a}$ & 14 \\
\hline \multirow{2}{*}{ P2 } & \multirow{2}{*}{ Subterrânea } & 1a & $<2$ \\
\hline & & 2a & $<2$ \\
\hline \multirow{2}{*}{ P3 } & \multirow{2}{*}{ Subterrânea } & 1a & 2 \\
\hline & & $2 \underline{a}$ & $<2$ \\
\hline \multirow{2}{*}{ P4 } & \multirow{2}{*}{ Superficial } & 1a & 4 \\
\hline & & $2 \underline{a}$ & 21 \\
\hline \multirow{2}{*}{ P5 } & \multirow{2}{*}{ Subterrânea } & 1a & 13 \\
\hline & & $2 \underline{a}$ & 15 \\
\hline \multirow{2}{*}{ P6 } & \multirow{2}{*}{ Subterrânea } & 1a & $<2$ \\
\hline & & $2 \underline{a}$ & $<2$ \\
\hline
\end{tabular}

Para caracterizar uma água, são determinados diversos parâmetros, os quais representam as suas características físicas, químicas e biológicas. Esses parâmetros são indicadores da qualidade da água e constituem impurezas quando alcançam valores superiores aos estabelecidos para determinado uso (ANA, 2020). As médias dos resultados dos principais indicadores de qualidade da água nos parâmetros físico e químico têm seus valores representados na Tabela 3.

Tabela 3: Resultados médios dos parâmetros físico-químicos das análises das amostras de água para uso na irrigação de hortaliças consumidas cruas.

\begin{tabular}{|c|c|c|c|}
\hline Propriedades & $\begin{array}{ll} & \text { p } \\
\text { H }\end{array}$ & Turbidez (UNT)* & Sólidos Totais (mg/L) \\
\hline P1 & 7,1 & 7,1 & 111,66 \\
\hline $\mathbf{P 2}$ & $5,5 * *$ & 0,25 & 53,33 \\
\hline P3 & 6,4 & 12,5 & 304,84 \\
\hline P4 & $5,7 * *$ & 4,9 & 70 \\
\hline P5 & $5,7 * *$ & 7,35 & 126,67 \\
\hline P6 & 7,1 & 8,2 & 143,33 \\
\hline Média Geral & 6,05 & 7,25 & 119,17 \\
\hline
\end{tabular}

*UNT- Unidade Nefelométrica de Turbidez. Valores com ** estão abaixo do padrão

Utilizou os dados obtidos nessa pesquisa para desenvolver uma correlação entre a turbidez e os sólidos totais, de forma a se obter valores mais próximos aos encontrados experimentalmente, através do teste de correlação de Pearson a qual apresentou $r=0,89$. Os resultados encontrados estão apresentados na Figura 3.

As amostras de água foram coletadas de agricultores familiares cuja produção é destinada a comércio, principalmente ao programa nacional de alimentação escolar (PNAE), que contribui para a boa alimentação escolar dos estudantes e para formação de hábitos alimentares saudáveis. Por tanto há a necessidade de utilizar água de boa qualidade que não seja prejudicial à saúde. Dentre os resultados obtidos as amostras de análise bacteriológica (Tabela 2) estão dentro do padrão exigido pela legislação. 
Portanto, algum fator que possa acarretar contaminação na água independente da fonte de captação ou na rede de distribuição possa está interligada a resíduos inorgânicos ou orgânicos provenientes de atividades humana e animal (MAROUELLI et al., 2014).

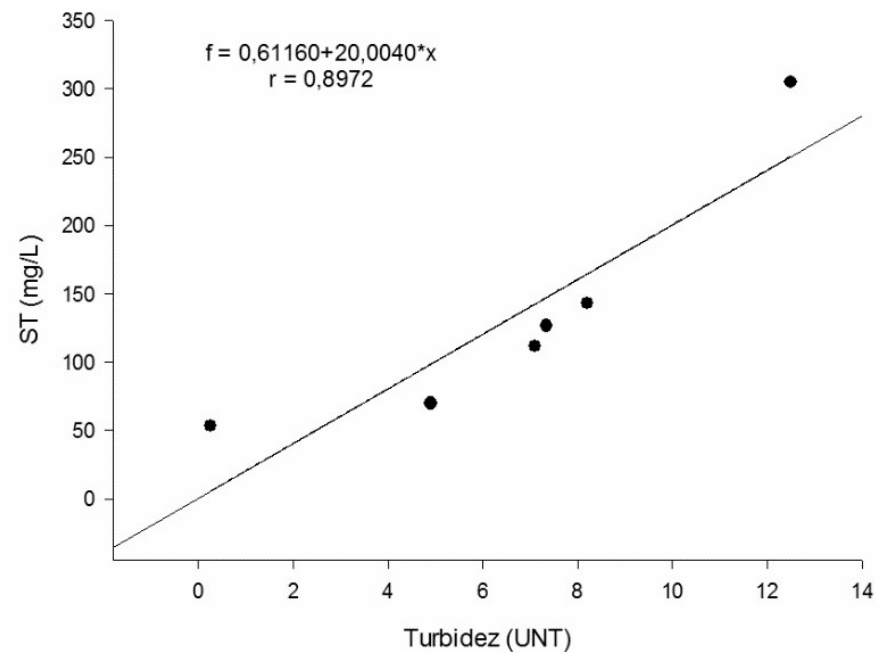

Figura 3: Correlação das concentrações de Turbidez com as de Sólidos Totais (ST) das amostras de águas das fontes das propriedades rurais.

Diante da escassez das águas superficiais o uso de fontes hídricas subterrâneas vem aumentado consideravelmente, como apresentado na Figura 2, que 67\% dos agricultores fazem uso de águas subterrâneas na irrigação de hortaliças. Vários países vêm adotando a utilização das águas subterrâneas como meio de suprimento hídrico (CARVALHO et al., 2020). Sua disponibilidade tem permitido muitas das vezes que haja permanência e sobrevivência nas propriedades rurais onde a precipitação e as águas superficiais são escassas e insuficientes (SOUZA et al., 2014).

Destacam-se os resultados obtidos das análises bacteriológicas (Tabela 2), cujas amostras analisadas estão dentro do padrão de qualidade segundo a resolução do CONAMA n³57/05 para irrigação de hortaliças (Tabela 1). As bactérias do grupo coliformes são consideradas os principais indicadores de contaminação fecal, assim assume a importância de ser um parâmetro indicador da possibilidade da existência de microrganismos patogênicos na qualidade da água, tendo como representante desse grupo a bactéria Escherichia coli (CETESB, 2015), cujo sua concentração na água possui relação direta com o grau de contaminação tornando a água imprópria para consumo (OLIVEIRA et al., 2017). A alimentação de hortaliças cruas que são produzidas em contato direto com águas contaminadas com microrganismos como coliformes, constituem fontes prováveis de intoxicação alimentar (RODRIGUES et al., 2020), as concentrações de coliformes podem aumentar na água com alterações de condições ambientais como: temperatura e presença de matéria orgânica (MASSAMBE et al., 2019). É importante ressaltar que devido maior parte da fonte da água usada para irrigação ser subterrânea, sendo importante ressaltar que o solo realiza um trabalho como filtro natural, assim reduz os riscos de contaminantes na água (AMARAL, 2003).

Com os resultados dos parâmetros físico-químicos (Tabela 3), apresentaram resultados dentro do padrão pela legislação do CONAMA. Porém a turbidez quando relacionando a analise para água com fins de consumo humano, não deve ultrapassar 5,0 UNT, segundo regulamentada pela portaria $\mathrm{n}^{\circ} 518$ do 
Ministério da Saúde (BRASIL, 2004). Schwartz et al. (2000), encontraram associação significativa entre índices de turbidez e admissão hospitalar por doenças gastrointestinais, entre a população de idosos na Filadélfia, Estados Unidos. Existe a preocupação em relação da forma de utilização da água, a fim de evitar qualquer contaminação, de modo, que as análises microbiológicas e físico-químicas são essências para identificar e apresentar diagnósticos a respeito da qualidade da água, dessa maneira, fazer a utilização de procedimentos adequados para desinfecção inibindo ação de patógenos e problemas econômicos.

Conforme os valores do resultado relacionados a turbidez (Tabela 3), encontram-se dentro do permitido para uso na irrigação, dessa forma não interfere no desenvolvimento da planta, já que os valores são em quantidades pequenas. Na propriedade P3, apresentou o valor mais elevado dentre as amostras, sendo de fonte de água subterrânea cuja profundidade ( 3 metros) de captação considerada rasa, porém se encontra dentro do permitido na legislação (Tabela 1), não havendo nenhum dano ao sistema produtivo. A turbidez pode reduzir a zona eufótica, que é a zona de luz onde a fotossíntese ainda é possível ocorrer com valores elevados acima do permitido (VEIGA, 2005), sendo que é nesta zona que ocorre a compensação da produção sobre as taxas de respiração, que acontecem nos períodos com e sem iluminação (TUNDISI et al., 2008). É comum esperar que águas subterrâneas de poços rasos apresentem certa turbidez, uma vez que são suscetíveis à carreamento de sólidos por erosão. Scorsafava et al. (2010) relatam que, muitas vezes águas subterrâneas apresentam características físicas compatíveis com os padrões de qualidade devido à ação de filtração lenta através das camadas permeáveis do solo, sendo assim águas subterrâneas profundas geralmente apresentam baixos teores de cor e turbidez, não sendo necessário sofrer processos de tratamento para alguns tipos de usos.

Nos resultados a respeito do parâmetro de sólidos totais, foi observado alto valor na propriedade P3 (Tabela 3), mesmo assim permanecendo dentro do permitido na legislação (Tabela 1), não foi relatado nenhum problema no sistema de irrigação, porém, devido a profundidade do poço subterrâneo ser raso, pode sofrer alterações devido a escoamento superficial e erosões carreando materiais inorgânicos e orgânicos a fonte de captação. Almeida (2010), relata que altas concentrações de sólidos na água podem levar à incrustações sobre a superfície dos equipamentos de irrigação, portanto, Souza et al. (2019), explica que as incrustações provocam entupimento significativos nos emissores na saída de água. Brito et al. (2020) descreve que o devido depósito de materiais orgânicos ou inorgânicos tais como: areia, argilas, carbonatos, ferro e organismos biológicos são prejudiciais ao sistema de irrigação. Santos et al. (2020) afirma alteração na qualidade de água devido a maior lixiviação e percolação de contaminantes e matérias inertes em águas superficiais e subterrâneas em períodos chuvosos.

Ao analisar os parâmetros físicos existe uma correlação positiva clara entre os valores de turbidez e de sólidos totais, amostrados na Figura 3 (Índice de correlação $=0,89$ ), mostrando que quando há muitos sólidos na água há uma tendência da turbidez ser maior, o que indica uma correlação significativa. Esses sólidos totais referem-se à quantidade de material suspenso e dissolvido que está presente na água (FRAVET et al., 2007), por tanto a turbidez é a medida do desvio da luz pela ação de partículas suspensas orgânicas e inorgânicas, fator este determinante nos valores de transparência (VON SPERLING, 2005). 
Quando avaliado o parâmetro químico (Tabela 3) os valores do $\mathrm{pH}$, apresentam $50 \%$ das propriedades com resultado abaixo do padrão referente a legislação (Tabela 1), sendo as amostras P2, P4 e P5 com valor inferior ao determinado, apresentando caráter ácido. O valor baixo encontrado para o pH pode estar relacionado a profundidade do poço, conforme o Rodrigues et al. (2020) que obteve registro de valores menores de $\mathrm{pH}$ em poços de menor profundidade. Já em água superficial tal fato pode ser explicado por ter contato com matéria orgânica, originados por criações de animais por perto, Santos et al. (2020) afirma que com aumento dos ácidos orgânicos na água ocasiona a diminuição do pH tornando ácido, assim os valores de pH podem ser reflexo das características do solo e da fonte de captação de água. Não houve relato de problemas do sistema de irrigação nas propriedades avaliadas, mas Silva et al. (2011) e Carvalho et al., (2020) afirmam que a acidez da água pode contribuir para a corrosão das estruturas das instalações hidráulicas.

As amostras analisadas apresentaram boa qualidade da água para fins de irrigação de hortaliças, visto principalmente por maior parte da captação da água ser de fonte subterrânea (Figura 2), uma vez que a água pode ser um dos meios de contaminação mais influentes. De acordo com Mesquita et al. (2015), a qualidade da água é um dos aspectos mais importantes da produção de hortaliças, estando relacionada diretamente com o uso nas irrigações, no entanto água fora dos padrões compromete a produção agrícola inviabilizando a comercialização. Diante a utilização de sistema de irrigação existe o risco de danos e prejuízos econômicos, no qual Vasconcelos et al. (2013) e Dahan et al. (2014), afirmam que à água fora dos padrões de qualidade podem danificar o sistema de irrigação e causar um grande impacto negativo para o ambiente.

\section{CONCLUSÕES}

A água utilizada para irrigação apresentou metade (50\%) das amostras com pH ácido (abaixo de 6,0), já nos aspectos físicos e biológicos se encontraram dentro dos parâmetros exigidos na resolução $n^{\circ}$ 375/05 do CONAMA para águas de Classe 1, destinadas a hortaliças consumidas cruas. Em virtude do que foi analisado, tem-se que as amostras de água, de um modo geral, têm uma boa qualidade para fins de irrigação de hortaliças. Para resultados mais precisos torna-se necessário a realização do acompanhamento (do monitoramento) dos parâmetros indicadores de qualidade da água de irrigação durante um período sistêmico.

\section{REFERÊNCIAS}

ABREU, C. H. M.; CUNHA, A. C.. Qualidade da água em ecossistemas aquáticos tropicais sob impactos ambientais no baixo Rio Jari. Biota Amazônia, v.5, n.2, p.119-131, 2015. DOI: http://doi.org/10.18561/21795746/biotaamazonia.v5n $\underline{2 p 119-131}$

ALMEIDA, O. A.. Qualidade da Água de Irrigação. Embrapa Mandioca e Fruticultura, 2010.

ALMEIDA, C.; QUINTAR, S.; GONZÁLEZ, P.; MALLEA, M. Assessment of irrigation water quality. A proposal of a quality profile. Environmental monitoring and assessment, v.142, n.3, p.149-152, 2008. DOI https://doi.org/10.1007/s10661-007-9916-7

ALVES, A. S.; LIMA, V. L. A.; NETO, J. D.; LIMA JÚNIOR, B. C. L.; MELO JÚNIOR, A. P.. Qualidade da água residuária aplicada à cultura da bananeira. Brazilian Journal of Animal and Environmental Research, v.4, n.1, p.511-531, 2021. DOI: https://doi.org/10.34188/bjaerv4n1-045

AMARAL, L. A.; NADER FILHO, A.; ROSSI JÚNIOR, A. D.; FERREIRA, F. L. A.; BARROS, L. S. S.. Água de consumo humano como fator de risco à saúde em propriedades rurais. Revista de Saúde Pública, v.4, n.37, p.510-514, 2003. 
ANA. Agência Nacional de Águas. Atlas irrigação: uso da água na agricultura irrigada. Brasília, 2020.

APHA. American Public Health Association. Standard methods for the examination of water and wastewater. 21 ed. Washington: American Public Health Association, 2005.

BRASIL. Ministério da Saúde. Portaria n. 518 de $\mathbf{2 5}$ de março de 2004. Norma de qualidade da água para consumo humano. Brasília: DOU, 2004.

BRASIL. Ministério do Meio Ambiente. Resolução n.357. Dispõe sobre a classificação dos corpos de água e diretrizes ambientais para o seu enquadramento, bem como estabelece as condições e padrões de lançamento de efluentes, e dá outras providências. Brasília: DOU, 2005.

BRITTO, F. B.; VASCO, A. N.; MORAIS, G. F. O.; AGUIAR NETTO, A. O.. Técnicas estatísticas para análise da qualidade da água em áreas irrigadas no baixo Rio São Francisco. Revista Ibero Americana de Ciências Ambientais, v.11, n.2, p.192-203, 2020. DOI: http://doi.org/10.6008/CBPC21796858.2020 .002 .0021

CARVALHO, L. L. S.; LACERDA, C. F.; CARVALHO, C. M.; LOPES, F. B.; ANDRADE, E. M.; GOMES FILHO, R. R.. Spatiotemporal variability of groundwater quality in an irrigated area in the Brazilian semiarid region. Research, Society and Development, v.9, n.8, 2020. DOI: https://doi.org/10.33448/rsd-v9i8.5786

CARVALHO, F. T.; VELINI, E. D.; CAVENAGHI, A. L.; NEGRISOLI, E.; CASTRO, R. M.. Influência da Turbidez da Água do Rio Tietê na Ocorrência de Plantas Aquáticas. Planta Daninha, v.23, n.2, p.359-362, 2005. DOI: https://doi.org/10.1590/S0100-83582005000200025

CETESB. Companhia Ambiental do Estado de São Paulo. Qualidade das águas superficiais no estado de São Paulo. São Paulo, 2015.

CETESB. Companhia Tecnológica de Saneamento Ambiental. Qualidade da água: Guia de coleta e preservação de amostras de água. São Paulo, 2005.

DAHAN, O.; BABAD, A.; LAZAROVITCH, N.; RUSSAK, E. E.; KURTZMAN, D.. Nitrate leaching from intensive organic farms to groundwater. Hydrology Earth System Sciences, v. 18, n.7, p.333-341, 2014. DOI: https://doi.org/10.5194/hess18-333-2014

FRAVET, A. M. M.; CRUZ, R. L.. Qualidade da água utilizada para irrigação de hortaliças na região de Botucatu-SP. Irriga, v.12, n.2, 2007. DOI: http://dx.doi.org/10.15809

IBGE. Instituto Brasileiro de Geografia e Estatística. Censo 2019. IBGE, 2019.

MAROUELLI, W. A.; MALDONADE, I. R.; BRAGA, M. B.; SILVA, H. R.. Circular técnica 134: Qualidade e segurança sanitária da água para fins de irrigação. Embrapa, 2014.

MASSAMBE, J. C.. ALVARENGA, K. A. S.; ABREU, M. C. JUNIOR, T. C. R.; RODRIGUES, L. G.; TAVARES, D. C.. Avaliação da qualidade da água em propriedades de agricultura familiar de Muriaé e região. In: JORNADA DE INICIAÇÃO CIENTÍFICA DO UNIFACIG, 4. Anais. Manhuaçu, 2019.
MELO, M. T.; QUEIROZ, T. M.; VINAGA, L.; FERREIRA, J. R. S. Qualidade da água para a irrigação, a sustentabilidade de uma bacia hidrográfica-riacho queima pé, Tangará da Serra/MT. Caminhos de Geografia, v.21, n.76, p.16-27. DOI: https://doi.org/10.14393/RCG217646064

MESQUITA, D. R.; SILVA, J. P.; MONTE, N. D. P.; SOUSA, R. L. T.; SILVA, R. V. S.; OLIVEIRA, S. S.; LEAL, A. R. S.; FREIRE, S.

M.. Ocorrência de parasitos em alface crespa (Lactuca sativa L.) em hortas comunitárias de Teresina, Piauí, Brasil. Revista Patologia Tropical, v.44, n.1, p.67-76, 2015. DOI: https://doi.org/10.5216/rpt.v44i1.34802

NTS. Norma Técnica SABESP. NTS 013, São Paulo, 1999.

OLIVEIRA, W. F.; PINTO, O. B.. Análise microbiológica da qualidade das águas do rio Cuiabá perímetro urbano, a partir de quatro pontos de amostragem. Uniciências, v.21, n.2, p.56-59, 2017. DOI: https://doi.org/10.17921/14155141.2017v21n2p56-59

RODRIGUES, J. B.; SILVA, D. D. S.; FREITAS, S. J. N.; CABRAL, A. C. L. C.; PFEIFF, G. K.; AMORIM, I. L. S.. Qualidade da água utilizada na irrigação de produtos orgânicos: o caso de um polo agrícola em Paço Lumiar/MA. Nature and Conservation, v.13, n.1, p.16-21, 2020. DOI: http://doi.org/10.6008/CBPC2318-2881.2020.001.0003

REIS, C. F.; VILAS BOAS, M. A.; MERCANTE, E.; HERMES, E.; REISDORFER, M.. Avaliação da qualidade da água para irrigação em Salto do Lontra-PR. Engenharia Ambiental: Anais, v.8, n.1, p.69-78, 2011.

SANTOS, L. F.; MARINHO, E. R.; MOREIRA, F. S. A.; CARNEIRO, B. S.; FAIAL, K. C. F.. Avaliação da qualidade da água da baía do Guajará em Belém/PA. Revista Ibero Americana de Ciências Ambientais, v.11, n.2, p.367-380, 2020. DOI: http://doi.org/10.6008/CBPC21796858.2020 .002 .0034

SCHNABEL, U.; NIQUET, R.; KROHMANN, U.; WINTER, J.; SCHLÜTER, O.; WELTMANN, K. D.; EHLBECK, J..

Decontamination of microbiologically contaminated specimen by direct and indirect plasma treatment. Plasma Processes and Polymers, n.6, p.569-575, 2012. DOI: http://doi.org/10.1002/ppap.201100088

SCHWARTZ, J.; LEVIN, R.; GOLDSTEIN, R.. Drinking water turbidity and gastrointestinal illness in the elderly of Philadelphia. Journal of Epidemiology \& Community Health, v.54, n.1, p.45-5, 2000. DOI:

http://dx.doi.org/10.1136/jech.54.1.45

SCORSAFAVA, M. A.; SOUZA, A.; STOFER, M.; NUNES, C.A.; MILANEZ, T. V.. Avaliação físico-química da qualidade de água de poços e minas destinada ao consumo humano, Rev. Inst. Adolfo Lutz, v.69, p.229-232, São Paulo, 2010.

SILVA, I. N.; FONTES, L. O.; TAVELLA, L. B.; OLIVEIRA, J. B.; OLIVEIRA, A. C.. Qualidade de água na irrigação.

Agropecuária Científica no Semi-Árido, v.7, n.3, p.1-15, 2011. DOI: http://dx.doi.org/10.30969/acsa.v7i3.134

SOUZA, A. A.; LASTORIA, G.; GABAS, S. G.; MACHADO, C. D. Avaliação da água subterrânea nos aquíferos cenozoico e guarani em São Gabriel do Oeste-MS: subsídios à gestão integrada. Ciência e Natura, v.36, n.2, p.169-179. DOI: https://doi.org/10.5902/2179460X13174 
SOUZA, C. A.; QUEIROZ, T. M.. Qualidade água na bacia hidrográfica do Rio das Garças/MT para fins de irrigação. Revista Ibero Americana de Ciências Ambientais, v.11, n.1, p.157-164, 2020. DOI: http://doi.org/10.6008/CBPC2179$\underline{6858.2020 .001 .0015}$

SOUZA, M.; RIBEIRO, A, A.. Qualidade da água para fins de irrigação em regiões áridas e semiáridas. Brazilian Journal of Biosystems Engineering, v.13, n.4. p.355-359, 2019. DOI: http://dx.doi.org/10.18011/bioeng2019v13n4p355-359

TUNDISI, J. G.; TUNDISI, T. M.. Limnologia. São Paulo: Oficina de Textos, 2008.
VASCONCELOS, R. S.; LEITE, K. N.; CARVALHO, C. M.; ELOI, W. M.; SILVA, L. M. F.; FEITOSA, H. O.. Qualidade da água utilizada para irrigação na extensão da microbacia do Baixo Acaraú. Revista Brasileira de Agricultura Irrigada, v.3, n.1, p. 30-38, 2013. DOI:

http://dx.doi.org/10.7127/RBAI.V3N100014

VEIGA, G.. Análises físico-químicas e microbiológicas de água de poços de diferentes cidades da região sul de Santa Catarina e efluentes líquidos industriais de algumas empresas da grande Florianópolis. Dissertação (Mestrado em Química) - Universidade Federal de Santa Catarina, Florianópolis, 2005.

VON SPERLING, M.. Introdução à qualidade das águas e ao tratamento de esgoto. 3 ed. Belo Horizonte: Universidade Federal de Minas Gerais, 2005.

A CBPC - Companhia Brasileira de Produção Científica (CNPJ: 11.221.422/0001-03) detém os direitos materiais desta publicação. Os direitos referem-se à publicação do trabalho em qualquer parte do mundo, incluindo os direitos às renovações, expansões e disseminações da contribuição, bem como outros direitos subsidiários. Todos os trabalhos publicados eletronicamente poderão posteriormente ser publicados em coletâneas impressas sob coordenação da Sustenere Publishing, da Companhia Brasileira de Produção Científica e seus parceiros autorizados. Os (as) autores (as) preservam os direitos autorais, mas não têm permissão para a publicação da contribuição em outro meio, impresso ou digital, em português ou em tradução. 